\section{Third molar-related morbidity in deployed Service personnel}

\author{
J. Combes, ${ }^{1}$ E. McColl, ${ }^{2}$ B. Cross ${ }^{3}$ and R. J. McCormick ${ }^{4}$
}
IN BRIEF
- Confirms that third molar related pathology is a cause of disease and non- battle injury among troops deployed in Afghanistan and Iraq.
- Despite the presence of dental surgeons in the theatre of conflict, access to urgent dental care is not always possible.
- Emphasises the need to actively question service personnel about third molar symptoms and to complete outstanding treatment before deployment.

Introduction The minimisation of disease and non-battle injury (DNBI) is essential for maintaining efficiency in a fighting force. Third molar-related morbidity is a common cause of DNBI. With extended lines of communication in current military deployments, travelling for dental care is often subject to significant danger. Material and methods Military dental officers in Afghanistan and Iraq recorded data on patients presenting with third molar pathology. Related previous history was obtained from the individual and from the military dental records. Results Three hundred and three individuals presented during the 23 month study period; $27.7 \%$ were unable to access care immediately, most commonly citing work pressure or lack of safe transport. Of those needing to travel, $70 \%$ were moved by helicopter. Pericoronitis was diagnosed in $84.4 \%$ of cases, $20.6 \%$ of these teeth being extracted; $53.5 \%$ of patients reported no prior symptoms, $22.7 \%$ with two or more episodes. There was documented evidence in military dental records of previous problems in $29.2 \%$ of cases. $11.3 \%$ had previously been listed for extraction of the presenting tooth. Discussion Dental treatment for troops in combat situations is fraught with difficulty. Special consideration must be given to the management of third molars in military personnel.

\section{INTRODUCTION}

Rates of disease and non-battle injury (DNBI) increase during combat phases of military deployment when compared with peacetime. ${ }^{1}$ Third molar pathology was a common cause of DNBI in the 2003 Gulf Conflict, with reported incidences ranging from 21-24/1,000 man years at risk (MYAR). ${ }^{2}$ Pericoronitis was responsible for $13 \%$ and 19\% of attendances for dental emergencies in UK and US service personnel respectively. ${ }^{2-4}$ In UK troops, 41\% of pericoronitis cases had 'moderate or serious operational impact'.

It is imperative that military medical services act to reduce DNBI to minimise suffering and maximise operational

\footnotetext{
${ }^{1 *}$ Lieutenant Colonel, Royal Army Medical Corps, Oral and Maxillofacial Unit, Royal Surrey County Hospital, Egerton Road, Guildford, GU2 7XX; ${ }^{2}$ Lieutenant Colonel, Royal Army Dental Corps, Defence Dental Services Training Establishment, Evelyn Woods Road, Aldershot, Hants, GU11 2LS: ${ }^{3}$ Major, Royal Army Dental Corps, Orthodontic Department, University of Wales College of Medicine, Cardiff, CF14 4XN; ${ }^{4}$ Colonel, Late/Royal Army Dental Corps, Defence Dental Services Headquarters, RAF Halton, Aylesbury, HP22 5PG

${ }^{*}$ Correspondence to: Lt Col James Combes Email: jgcombes@aol.com
}

\section{Refereed Paper}

Accepted 8 July 2010

DOI: $10.1038 /$ sj.bdj.2010.724

${ }^{\circ}$ British Dental Journal 2010; 209: E6 effectiveness, with the prevention of dentally-related morbidity an important tenet of this policy. Dental facilities (Fig. 1) cannot always be close to areas of operation, especially in current unconventional, asymmetric warfare in Afghanistan where soldiers are located in small, widely disparate groups. This results in loss of time in primary military roles and entails significant risk during transport to obtain dental or medical care, especially in this era of roadside improvised explosive devices (IEDs).

The aim of this study was to expand the evidence base on third molar morbidity and associated complications in providing care in a war zone and to revisit protocols designed to minimise risk in an operational environment.

\section{MATERIAL AND METHODS}

Military dental officers serving in Southern Afghanistan (October 2007 to August 2009) and Iraq (January 2009 to August 2009) recorded data prospectively using a standardised data entry form on all patients attending as an emergency with third molar-related complaints. The data recorded related to the nature of pathology, treatment received, reasons for delay

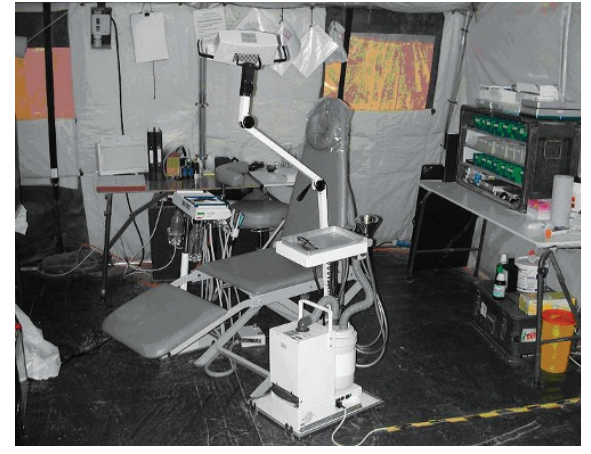

Fig. 1 A typical dental facility in the theatre of conflict

in accessing treatment and time lost from primary role. Patients were questioned about prior, similar episodes and details were authenticated against military dental records held in the UK. The aim was to establish if the offending tooth had been identified as problematic, what plan had been instituted and whether in hindsight this was appropriate. As transport risk became apparent, information was collected on travelling time and mode of transport for the period December 2008 to August 2009 in Afghanistan. This was to compare the experience of those who were based in the same location as the dentist (co-located personnel) with those who had to travel to obtain dental care 
(non-co-located personnel). Data on time to return to duty was not available as it was not possible to establish exactly when each individual had managed to return to duty once discharged.

\section{RESULTS}

In the 23 months studied, 303 service personnel with third molar complaints presented to the Defence Dental Services on 306 occasions (three patients presented twice). A total 314 third molars were symptomatic, 255 (81.2\%) of which were mandibular (11 patients had two symptomatic teeth). The median time that patients endured symptoms before deciding to report sick was three days (range 0-60).

Two hundred and nineteen (72.3\%) patients saw a dental surgeon on the day that they decided to report sick, with a further $26(8.6 \%)$ seen after a wait of one day. Forty-five (14.9\%) of the remaining 58 individuals were seen within a week. The median wait for the 84 delayed patients was two days (range 1-60). Delays were most commonly due to pressure of work or danger associated with travel at that juncture (Fig. 2).

In the last nine months of data collection (January-August 2009), more detailed information regarding patient location and travel was available for a total 168 patients, $41(24.4 \%)$ of whom were not co-located with a dental facility. Data was available on 34/41 of these cases. The median travelling time was 40 minutes, range 10 minutes to $48 \mathrm{hrs}$; mode of travel is detailed in Figure 3. In seven cases this transport was arranged specifically for the individual concerned while all others shared routine transport. The median delay before obtaining care for troops not co-located with the dentist was two days $(\mathrm{n}=41$, range $0-30$, mean 3.29 days) compared with less than one day for those who were co-located ( $\mathrm{n}=127$, range $0-45$, mean 0.78 days).

Of the 286 patients with recorded data, 200 (69.9\%) lost no time from work before seeing the dentist and were discharged back to their place of duty immediately. For the remaining 86 patients (30.1\%) the median sick time was two days (mean 2.15, range 1-10).

Pericoronitis was the cause of symptoms in 265/314 teeth (84.4\%), most of which were lower wisdom teeth $(237 / 268)$ (Fig. 4). Two hundred and fifteen lower third molars had an angulation of eruption recorded; 148 (68.8\%) were vertically impacted (Fig. 4). Data regarding previous symptoms were recorded for 256/268 teeth with pericoronitis; 53.5\% (137) had been previously asymptomatic (Fig. 5).

Two hundred and forty-two cases were UK service personnel with military dental notes. Two hundred and three (83.9\%) records were available for review, the others either being in transit or the individual having left the Armed Services. In

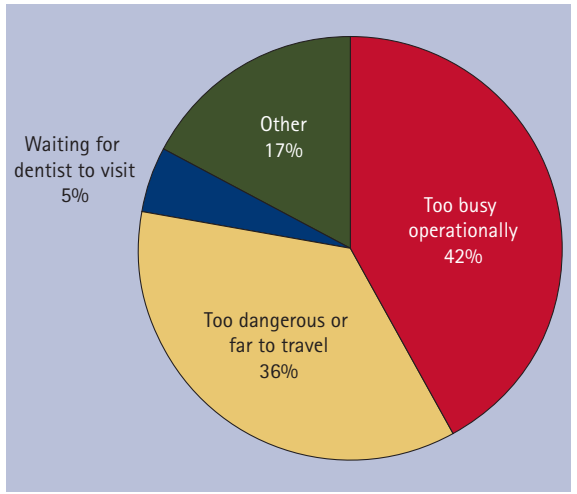

Fig. 2 Reasons for delay in acquiring treatment $(n=84)$

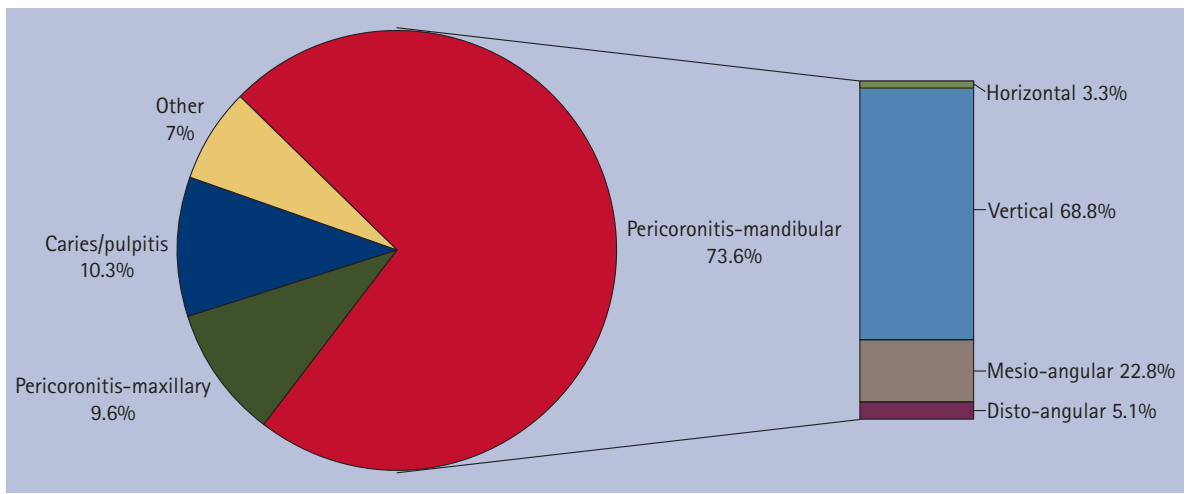

Fig. 4 Diagnoses and angulation of mandibular third molars affected by pericoronitis

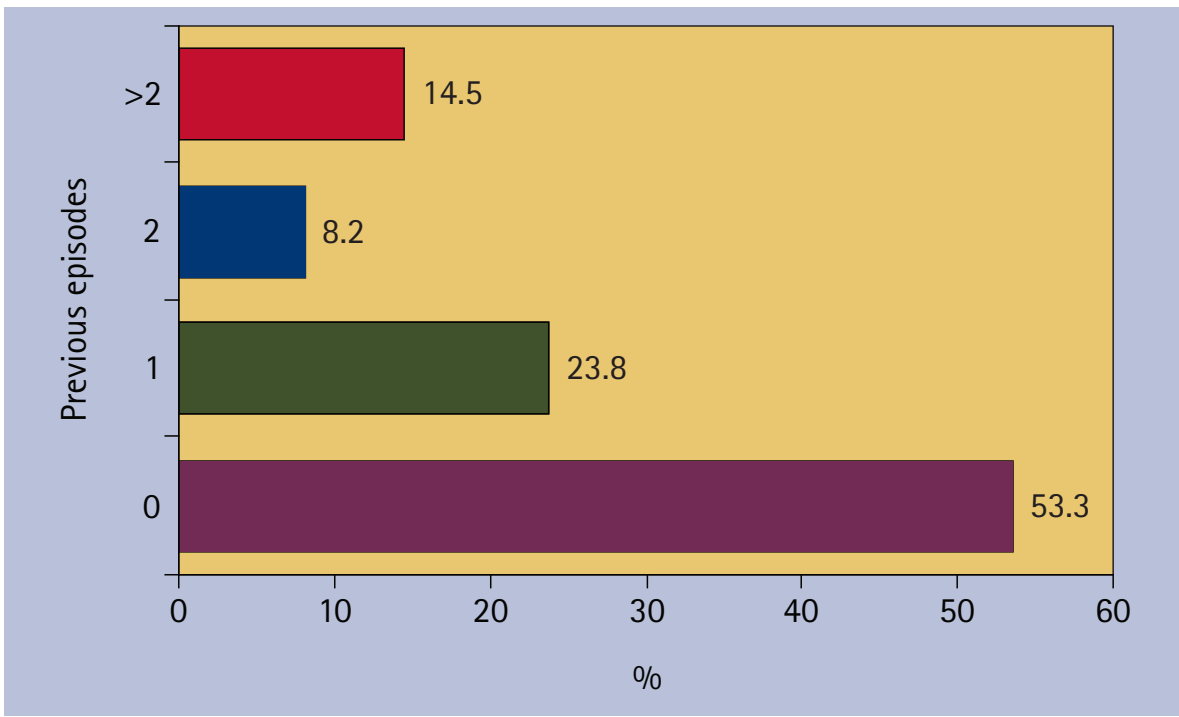

Fig. 5 Patient recollection of previous similar symptoms in cases of pericoronitis $(n=256)$ this sample of 203 there had been 212 symptomatic teeth. It was documented in notes that 62/212 (29.2\%) teeth had caused symptoms that resulted in the individual presenting to a military dentist before deployment. Thirteen patients had had the tooth in question listed for extraction under local anaesthetic and 11 had been referred to an oral and maxillofacial surgery (OMFS) unit, a total of 24 (11.3\%).

Treatment modality in theatre was documented for 301/314 (95.9\%) teeth.

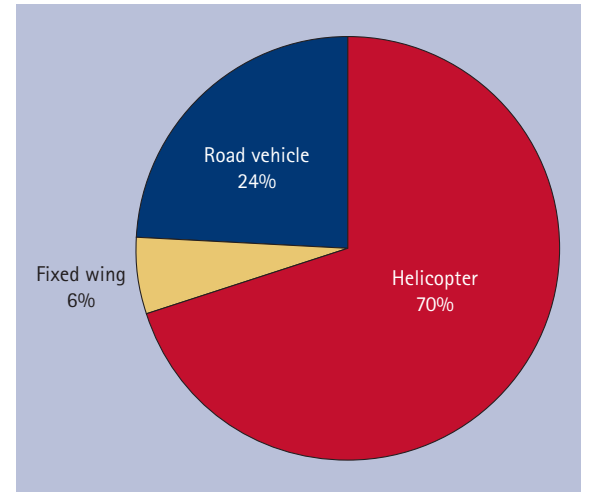

Fig. 3 Mode of transport for those not co-located with the dental centre 
Antibiotics were used in 129 cases (41.5\%), combined with debridement in 81 (26.9\%). Overall, 103 (34.2\%) symptomatic teeth were extracted, 62 (20.6\%) of which were related to pericoronitis.

\section{DISCUSSION}

National guidelines published in 1999 and 2000 by the Scottish Intercollegiate Guidelines Network (SIGN) ${ }^{5}$ and the National Institute for Health and Clinical Excellence (NICE), ${ }^{6}$ state that the prophylactic removal of pathology-free impacted third molars should be discontinued. The inference was that an unnecessary number of prophylactic exactions of wisdom teeth were being undertaken in the NHS at that time.

The NICE guidelines state that a first episode of pericoronitis, unless particularly severe, should not be considered as an indication for extraction but subsequent episodes are appropriate indications for surgery. The SIGN guidelines differ in that 'removal of any symptomatic wisdom tooth should be considered, especially where there have been one or more episodes of infection such as pericoronitis', qualifying this statement with 'removal of third molars is advised in patients with predisposing risk factors whose occupation or lifestyle precludes ready access to dental care'. The present data demonstrate the relevance of this doctrine to military personnel and shows the prescience of the 1997 Faculty of Dental Surgery of Royal College of Surgeons of England guidelines. They stated that 'in a patient who has borderline indications for third molar extraction and whose occupation will necessitate long periods away from civilisation (eg astronauts, nuclear submariners and explorers) consideration may be given to earlier rather than later third molar removal'? It is particularly pertinent as nuclear submariners may not surface for months at a time. ${ }^{8}$

Military policies for the management of third molars recognise that different standards are required for service personnel but they differ between nations and all rely on clinical judgement, which may be influenced by personal experience of theatres of conflict. ${ }^{9-12}$ US Military guidance seems to be most rigid, especially the Navy where individuals with 'unerupted (with oral communication) or partially erupted teeth that will not erupt into a functioning occlusion' are normally not considered to be worldwide deployable. US Army and Air Force guidelines are a little less stringent, with third molars recommended for removal if they are "unerupted, partially erupted or malaposed with historical, clinical or radiographic signs or symptoms or pathosis. ${ }^{11}$

British military policy on the subject is less interventionist and essentially follows NICE guidelines except that 'some personnel, for example, special forces, (who) are likely to deploy beyond easy access to medical support' who have third molars 'and who have a history of pericoronitis are to be referred for a consultant opinion on the requirement for removal if the clinician does not wish to undertake surgery themselves. ${ }^{10}$ Canadian Forces Dental Fitness Standards are similar, stating that 'third molars, in communication with the oral cavity, which are unlikely to erupt into a functional occlusion and have a history of repeated pericoronal infection, may preclude the dentally fit classification. ${ }^{12} \mathrm{~A}$ caveat is then given: "where the prognosis is unclear, individual occupation and operational commitments must be taken into consideration.' The Australian Defence Force Directive, which has recently been updated, also essentially follows NICE. ${ }^{9}$ Again exceptions are made based on role in that those who "work in a covert environment' or 'are isolated from emergency surgical care for extended periods, eg submariners, special forces and some aircrew' should have the risks explained to them so that they can 'make an informed decision regarding the prophylactic removal of their third molars'. Hence it is imperative that clinicians are aware of the situation in which service personnel are likely to find themselves in current conflicts.

Mahoney \& Coombs $^{13}$ reviewed dental casualty rates before the most recent conflicts in Afghanistan and Iraq, finding that in wars and conflicts the incidence of dental emergencies was 150-200 per 1,000 man years at risk (MYAR) for a wellprepared, all-volunteer force. This was confirmed by figures from the Gulf (2003) and Bosnian conflicts. ${ }^{2-4,14,15}$ The exact proportion attributable to third molar-related disease is not reported, but the incidence of pericoronitis ranges from 13-19\%..$^{2-4}$ In British troops during the war-fighting phase of the recent Iraqi conflict, the incidence of third molar-related pathology was 21-24 per 1,000 MYAR. ${ }^{4}$ Pericoronitis was the commonest dental cause of inability of an individual to perform his or her operational role. ${ }^{4}$ In this same theatre of war a year later after the initial conflict, the rate of third molar related pathology was still 24 per 1,000 MYAR, 78\% of which was related to pericoronitis. ${ }^{16}$ Unpublished Defence Dental Services figures show the incidence in Afghanistan during the period of this review as 18.1 per 1,000 MYAR. This fall may be the result of greater preparation time that units now have before deployment to the more established theatre of warfare.

Consideration must be given to the fact that only $24 \%$ of patients seen during this survey were not co-located with a dental centre. This is believed to be of great interest as a considerably larger proportion of the troops in theatre are not co-located with a dental facility (exact figures cannot be stated). It is entirely possible, indeed anecdotally the case, that treatment is instituted by local medical officers or team medical assistants in an attempt to prevent unnecessary, risk-laden transfer to see the dentist, with only severe or recalcitrant cases being transferred.

Pericoronitis accounts for $84.4 \%$ of cases in this series, with vertically impacted teeth accounting for $68.8 \%$, 22.8\% mesio-angular, 5.1\% disto-angular and 3.3\% horizontal. This compares with reported angulation in US Air Force recruits of 32.5\%, 51.5\%, $7.9 \%$ and $7.8 \%$ respectively. ${ }^{17}$ Further work is required to ascertain the exact risk that each angulation presents, including accurate prevalence figures.

of particular interest is the finding that less than half of patients reporting sick claimed that they had previously experienced problems from the tooth in question; furthermore, when military dental records were checked, only $29 \%$ had recorded evidence of symptoms before deployment. The implication is that if NICE guidelines, where two or more episodes of third molar symptoms are required before third molars are extracted, are applied in the military, then less than one third of cases would have been eliminated in this series. It is important to note from the review of dental records that 24 individuals had been listed to have the third molar in question 
removed, but this had not been completed before deployment, indicating preventable disease. This highlights the need to ensure that required treatment is performed before deployment, a situation that is often complicated by hectic training schedules and when symptoms occur close to the date of deployment.

The median time that personnel endured symptoms before deciding to report sick was three days, which is probably to be expected as individuals hope that symptoms will settle naturally. Once the decision to report sick had been made, the time to obtaining care is admirably short, with $72.3 \%$ seeing a dentist the day that they wished. The median wait for troops co-located with a dentist was less than a day, while this was two days for those who had to travel. While this likely still exceeds the standard experienced in civilian life, the reality is that toothache necessitating travel can be life threatening due to the risk of IEDs. This is reflected in the preponderance of helicopter transfers, although individuals are still exposed to risk in this medium of transport. Of most concern are the seven cases where transport had to be specifically arranged, which endangers others as well as the patient.

Overcoming this problem is difficult in an environment where troops are spread out in small units over huge areas, with significant danger associated with travel. There have been efforts by dental teams in theatre to counter this by visiting outposts on a regular basis. However, many bases have small troop numbers and dental morbidity needs immediate care, making this an inefficient use of dental resources.

\section{CONCLUSION}

The evidence from this study, and other information sources, indicate that the management of third molars is of considerable importance for the military population. In the majority of cases symptoms occurred de novo, with less than one quarter having had two or more previous episodes. This questions the use of NICE guidance and begs the creation of a specific military policy that minimises this morbidity while not exposing individuals to unnecessary surgery.

Current morbidity would have been reduced if planned treatment had been completed before deployment. As the rate of claimed previous symptoms was almost double the incidence recorded in personal dental documents, it may also have made a positive impact if individuals had been directly questioned about prior symptoms at routine check-up appointments.

It is hoped that any future review of NICE/SIGN guidelines will recognise military service as a possible indicator for surgical intervention. However, it is acknowledged that this work requires corroborative evidence and to this end, a prospective study of cohorts of soldiers in Afghanistan and a large scale, retrospective study of third molar natural history in military personnel are underway. The aim is to produce an evidence-based model that can be used to risk stratify third molars in service personnel, enabling appropriate treatment planning rather than a blanket policy of extraction.

1. Wojcik B E, Hassell L H, Humphrey R J, Davis J M Oakley C J, Stein C R. A disease and non-battle injury model based on Persian Gulf War admission rates. Am J Ind Med 2004; 45: 549-557.

2. Richardson PS. Dental morbidity in United
Kingdom Armed Forces, Iraq 2003. Mil Med 2005; 170: 536-541.

3. Dunn W J, Langsten R E, Flores S, Fandell J. Dental emergency rates at two expeditionary medical support facilities supporting operations Enduring and Iraqi Freedom. Mil Med 2004; 169: 510-514.

4. Dunn W J. Dental emergency rates at an expeditionary medical support facility supporting Operation Enduring Freedom. Mil Med 2004; 169: 349-353.

5. Scottish Intercollegiate Guidelines Network. Management of unerupted and impacted third molar teeth. Edinburgh: Scottish Intercollegiate Guidelines Network, 2000, publication no. 43. http://www.sign. ac.uk/guidelines/fulltext/43/index.html.

6. National Institute of Clinical Excellence. Guidance on the extraction of wisdom teeth. London: National Institute of Clinical Excellence, 2000, Technology Appraisal Guidance no.1. http://www.nice.org.uk/ nicemedia/pdf/wisdomteethquidance.pdf.

7. Faculty of Dental Surgery of the Royal College of Surgeons of England. Report of a working party convened by the Faculty of Dental Surgery. Current clinical practice and parameters of care. The management of patients with third molar (syn: wisdom) teeth. London: Faculty of Dental Surgery RCS(Eng), 1997. http://www.rcseng.ac.uk/fds/ publications-clinical-guidelines/clinical_guidelines/ documents/3rdmolar.pdf.

8. Deutsch M. Dental events during periods of isolation in the U S submarine force. Mil Med 2008; 173(1 Suppl): 29-37.

9. Surgeon General Australian Defence Force. Management of third molars in the Australian Defence Force. Health Bulletin Number 15/2009. Canberra: DHS, 2009.

10. Surgeon General. Clinical policy and standards for the management of third molar teeth. Surgeon General's Policy and Standards Document 2008, Section 2H1. London: MOD, 2008.

11. King J. Historical perspective on US Military dental classification. Mil Med 2008; 173(1 Suppl): 3-10.

12. Groves R. Dental fitness classification in the Canadian Forces. Mil Med 2008; 173(1 Suppl): 18-22.

13. Mahoney G D, Coombs M. A literature review of dental casualty rates. Mil Med 2000; 165: 751-756.

14. Chaffin J, King J E, Fretwell L D. U S Army dental emergency rates in Bosnia. Mil Med 2001; 166: 1074-1078.

15. Moss D L. Dental emergencies during SFOR 8 in Bosnia. Mil Med 2002; 167: 904-906.

16. Breeze J, Gibbons A. Are soldiers at increased risk of third molar symptoms when on operational tour in Irag? A prospective cohort study. J R Army Med Corps 2007; 153: 102-104.

17. Hollier J, Bartoloni K, Vandewalle K, Meyer K. Analysis of third molar prevalence and classification among military trainees. Presented at AADR Annual Meeting 2010, Washington DC, USA. http://iadr. confex.com/iadr/2010dc/webprogram/Paper 127502. html. 